\title{
IMPLEMENTASI ALGORITMA SPRITZ DAN SPREAD SPECTRUM UNTUK MENYEMBUYIKAN PESAN ENKRIPSI KEDALAM FILE AUDIO MP3
}

\author{
Muhammad Iqbal $^{1}$, Taronisokhi Zebua ${ }^{2}$, Ronda Deli Sianturi ${ }^{3}$ \\ ${ }^{1,2}$ Program Studi Teknik Informatika STMIK Budi Darma, Medan, Indonesia \\ ${ }^{3}$ Program Studi Teknik Informatika AMIK Stiekom Sumatera Utara, Rantau Parapat, Indonesia \\ Email: ${ }^{1}$ m.iqbal121297@gmail.com, ${ }^{3}$ taronizeb@gmail.com
}

\begin{abstract}
Abstrak
Pengamanan pesan teks yang bersifat rahasia sangat penting untuk menjaga isi pesan dari pihak-pihak yang ingin melakukan pemanfaatan ataupun pengerusakan terhadap pesan tersebut. Pemanfaatan teknik kriptografi dalam mengamankan data masih dapat menimbulkan kecurigaan terhadap pesan yang telah diamankan tersebut. Penelitian ini menguriakan bagaimana memanfaatkan teknik steganografi untuk melapisi pengamana pesan yang telah dienkripsi berdasarkan teknik steganografi. Algoritma spritz merupakan algoritma kriptografi yang digunakan untuk meperoleh sandi dari pesan asli, sedangkan metode spread spectrum merupakan metode yang digunakan untuk menyemunyikan sandi data asli ke dalam sebuah citra. Berdasarkan pengujian yang dilakukan pengkombinasian dua teknik ini cukup handal untuk mengoptimalkan keamanan pesan rahasia karena keberadaan sandi data asli tidak dapat dilihat secara kasat mata oleh orang lain.
\end{abstract}

Kata Kunci: Kriptografi, Steganografi, Spritz, Spread Spectrum, mp3

\begin{abstract}
Optimizing the security of confidential text messages is very important to protect the contents of messages from those who want to use or damage the message. The use of cryptographic techniques in securing data can still raise suspicion of the message that has been secured. This study explores how to use steganography techniques to coat encrypted message security based on steganography techniques. The spritz algorithm is a cryptographic algorithm that is used to obtain the cipher from the original message, while the spread spectrum method is a method used to hide the original data password into an image. Based on testing done by combining these two techniques, it is quite reliable to optimize the security of secret messages because others cannot see the existence of the cipher of the original data in plain sight.
\end{abstract}

Keywords: Cryptography, Steganography, Spritz, Spread Spectrum, mp3

\section{PENDAHULUAN}

Banyaknya cara yang dilakukan untuk mengamankan dan melindungi informasi yang bersifat rahasia dari orangorang yang tidak berhak terhadap informasi tersebut, salah satunya adalah informasi dalam bentuk pesan teks. Pengamanan pesan teks yang bersifat rahasia merupakan hal yang sangat penting untuk menjaga keaslian isi pesan dari pihak-pihak yang dapat merugikan pemilik pesan dengan cara merusak atau mengambil isi dari pesan tersebut demi keuntungan pribadi atau kelompok [1][2].

Salah satu upaya yang dapat dilakukan untuk meningkatkan keamanan pesan terutama pesan penting atau rahasia adalahpenggunaan teknik kriptografi dan steganografi. Teknik kriptografi digunakan untuk melakukan proses enkripsi dan dekripsi pesan sehingga pesan tersebut tidak dapat dibaca dan dipahami artinya, sedangkan teknik steganografi digunakan untuk menyembunyikan suatu pesan kedalam sebuah objek. Pengkombinasian antara kriptografi dan steganografi dapat meningkatkan keamanan pesan dengan cara mengenkripsi pesan dan menyisipkan pesan ke dalam sebuah media cover tanpa merubah kualitas dari cover [3].

Penelitian ini menguraikan proses pengamanaan pesan berupa teks yang akan dienkripsi dan dekripsi menggunakan algoritma kriptografi Spritz, kemudian hasil enkripsi berupa chipertext akan disembunyikan kembali kedalam objek sebuah file audio berformat Mp3 yang menghasilkan audio mp3 stegano berdasarkan algoritma Spread Spectrum, penyembunyian ini disebut dengan proses embedding. Sedangkan proses pengembalian pesan teks rahasia dilakukan dengan proses ekstraksi berdasarkan algoritma Spread Spectrum. Hasil ekstraksi merupakan data chipertext dari algoritma Spritz yang akan didekripsi kembali, sehingga pesan teks rahasia dapat dioptimalkan keamananya dengan dua teknik pengamanan yang berbeda.

\section{TEORITIS}

\subsection{Audio}

Audio adalah suara yang dihasilkan oleh getaran suatu benda, agar dapat tertangkap oleh telinga manusia getaran tersebut harus kuat minimal $20 \mathrm{kali} /$ detik. Suara yaitu suatu getaran yang dihasilkan oleh gesekan , pantulan dan lainlain, antara benda-banda. Sedangkan gelombang yaitu suatu getaran yang terdiri dari Amplitudo dan juga waktu. Suara dibangun oleh periode [4].

\subsection{MP3}


Mp3 adalah suatu format audio yang dikembangkan oleh Fraunhoper Institude dengan memiliki bitrate 128 kbps. Dalam waktu yang singkat Mp3 menjadi format paling populer dalam dunia musik digital, sebab ukuran filenya yang kecil dan juga kualitasnya tidak kalah dengan CD Audio [4].

\subsection{Algoritma Spritz}

Algoritma Spritz adalah sebuah algoritma yang di perbaharui dari algoritma RC4 yang dilakukan oleh Ron Rivest dan Jacob Schultzpada 2014. Penamambahan elemen A yang relatif prima terhadap nilai N menjadi perbedaan antara algoritma Spritz dan RC4. Proses enkripsi algoritma Spritz adalah varian dari enkripsi algoritma RC4, dimana data atau pesan yang dienkripsi akan diproses dengan konsep streamcipher yaitu enkripsi satu persatu. Algoritma Spritz memiliki prosedur utama yangterdiri dari tiga proses [5], yaitu :

1. Key Scheduling Algorithm (KSA)

Pengacakan kunci sebanyak 256 kali dengan menggunakan tabel KSA.

2. Pseudo-Random GenerationAlgoritma (PRGA)

Pseudo-Random GenerationAlgoritma (PRGA) atau pengacakan dilakukan untuk mendapatkan kunci baru dengan sejumlah elemen - elemen polos sehingga menghasilkan nilai outout $z$.

3. Proses enkripsi dan dekripsi dilakukan dengan cara XOR-biner setiap output $\mathrm{z}$ dengan masing-masingelemen polos dalam aliran.

Rumus enkripsi :

$\mathrm{C}_{\mathrm{i}}=\mathrm{P}_{\mathrm{i}} \mathrm{XOR}_{\mathrm{i}}$

Rumus dekripsi :

$\mathrm{P}_{\mathrm{i}}=\mathrm{C}_{\mathrm{i}} \mathrm{XOR}_{\mathrm{i}}$

\subsection{Algoritma Spread Spectrum}

Spread Spectrum adalah sebuah metode komunukasi yang menyebar sinyal informasi keseluruh frekuensi yang tersedia. Spread Spectrum memilih tempat penyisipan data pada frekuensi yang rendah. Dengan menambahkan pseudo-noise ( $\mathrm{PN})$, watermark akan disebar ke frekuensi yang luas amlitudonya bahkan bisa berada dibawah amplitudo pseudo-noise (PN) tersebut, sehingga semakin sulit untuk diteksi. Algoritma Spread Spectrum memiliki dua proses [6], yaitu :

1. Embedding

a. Penyebaran biner ciphertext menggunakan skalar empat.

b. Pembangkitan pseudonoise menggunakan operasi xor terhadap nilai biner kunci embedding.

c. Nilai hasil pseudonoise akan digunakan sebagai seedm random untuk membangkitkan bilangan Linear Congruential Generator (LCG) menggunakan rumus :

$X_{n+1}=\left(a X_{n}+c\right) \bmod m \ldots(3)$

d. Melakukan proses modulasi, biner segmen pseudonoise di xor dengan biner segmen ciphertext.

e. Biner-biner hasil modulasi disisipkan ke dalam biner audio mp3 dengan menggunalan LSB.

2. Ektraksi

a. Pengembalian biner-biner yang telah disispkan ke dalam audio mp3.

b. Pembangkitan pseudonoise menggunakan operasi xor terhadap nilai biner kunci embedding.

c. Nilai hasil pseudonoise akan digunakan sebagai seedm random untuk membangkitkan bilangan Linear Congruential Generator (LCG) menggunakan rumus :

$X_{n+1}=\left(a X_{n}+c\right) \bmod m \ldots(3)$

d. Melakukan proses demodulasi, biner segmen pseudonoise di xor dengan biner-biner yang telah disispkan.

e. Biner-biner hasil demodulasi diperkecil sehingga menghasilkan ciphertext.

\section{ANALISA DAN PEMBAHASAN}

Sebuah pesan teks yang bersifat rahasia sangat rentang terhadap pengambilan data oleh pihak yang tidak semestinya berhak akan pesan tersebut demi keuntungan pribadinya ataupun kelompok. Kurangnya tingkat keamanan seperi penyandian dan penyembunyian terhadap pesan teks tersebut memudahkan pihak-pihak yang tidak tekait mengambilnya, terutama pada pesan teks yang belum disandikan. Pada penelitian ini akan melakukan proses enkripsi dan dekripsi terhadap file teks yang berformat txt serta penyembunyian teks ke dalam media cover audio berformat mp3. Adapun proses enkripsi dan embedding dengan teknik kriptografi serta steganograi dapat dilihat pada diagram berikut : 


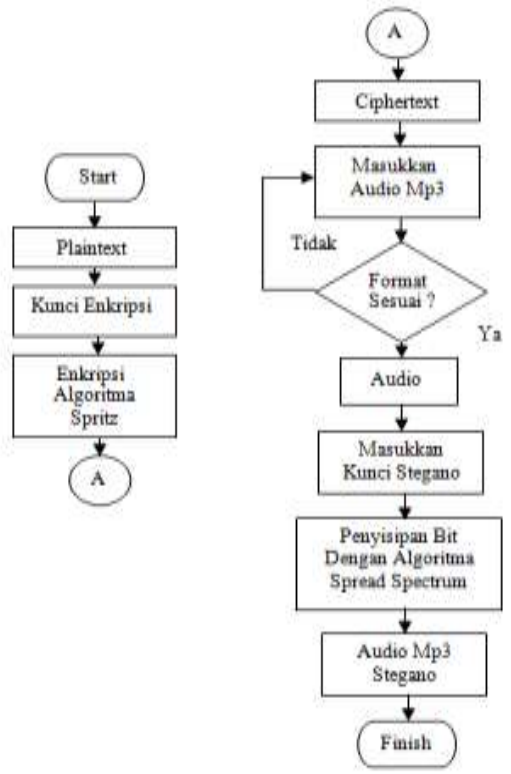

Gambar 1. Diagram Enkripsi dan Embedding

Pengembalian pesan teks yang telah disembunyikan kedalam file audio Mp3 digunakan proses dekripsi dan ekstraksi, dimana proses dekripsi akan mengembalikan pesan teks yang telah dienkripsi ke dalam bentuk awal pesan teks dan proses ekstraksi akan mengembalikan pesan teks yang telah disembunyikan ke dalam file audio Mp3. Adapun proses ekstraksi dan dekripsi dengan teknik kriptografi serta steganografi dapat dilihat pada diagram berikut :
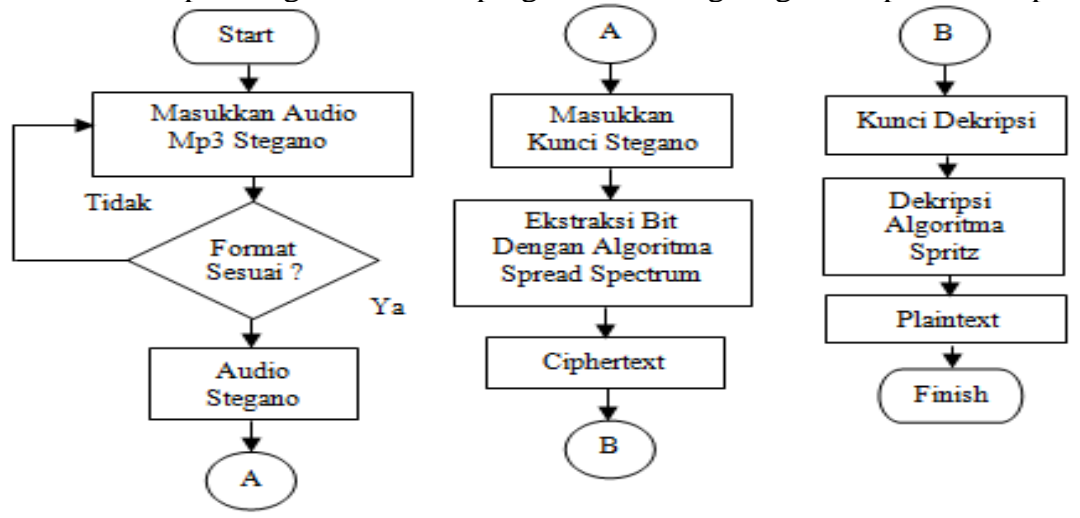

Gambar 2. Diagram Dekripsi dan Ekstraksi

\subsection{Penerapan Algoritma Spritz dan Spread Spectrum}

Penerapan algoritma Spritz dan algoritma Spread Spectrum dalam kasus ini akan diuraikan penerapan enkripsi dan dekripsi sebuah pesan teks dengan menggunakan algoritma Spritz lalu akan disembunyikan ke dalam file audio yang berformat Mp3 dengan proses embedding dan ekstraksi menggunakan algoritma Spread Spectrum. Plaintext dalam kasus ini adalah sebuah file berisikan pesan yang bertuliskan kata "IQBAL" dengan format txt, serta menggunakan kunci yaitu "2019". Sampel audio Mp3 yang digunakan adalah sebuah lagu "iwan fals - aku milikmu" dengan size yaitu 3.470.271 byte dan kunci "kami".

1. Proses Enkripsi Berdasarkan Algoritma Spritz

Langkah key scheduling dimulai dengan menginisialisasikan state awal berupa larik yang terdiri dari 256 elemen.

Proses ini membutuhkan nilai-nilai kunci awal yang telah dipetakan dalam bentuk matrix.

Tabel 1. Nilai Kunci Awal

\begin{tabular}{ccccc}
\hline Index & 0 & 1 & 2 & 3 \\
Kunci & 2 & 0 & 1 & 9 \\
Desimal & 50 & 48 & 49 & 57 \\
\hline
\end{tabular}

Kemudian dilakukan perhitungan nilaijyang pertama dengan nilai awal $i=0$ dan $j=0$ sebagai berikut :

$$
\begin{aligned}
& j=(j+S[i]+k e y[i \bmod \text { keylength }]) \bmod 256 \\
& j=(0+S[0]+k e y[0 \bmod 4] \bmod 256 \\
& j=(0+0+50) \bmod 256 \\
& j=50 \bmod 256
\end{aligned}
$$




$$
j=50
$$

Nilai $S[i]=S[0]$ swap dengan nilai $S[j]=S[50]$ maka,

Nilai $S[0]=50$ dan nilai $S[50]=0$

Perhitungan tersebut dilakukan sebanyak 256 kali sehingga menghasilkan tabel KSA :

Tabel 2. Hasil Key Scheduling Algorithm(KSA)

\begin{tabular}{cccccccccccccccc}
\hline 207 & 234 & 45 & 53 & 150 & 195 & 74 & 173 & 124 & 140 & 64 & 228 & 2 & 54 & 206 & 141 \\
15 & 252 & 108 & 40 & 75 & 136 & 77 & 152 & 9 & 244 & 71 & 0 & 34 & 144 & 29 & 50 \\
23 & 81 & 33 & 73 & 21 & 3 & 222 & 158 & 86 & 32 & 96 & 214 & 37 & 47 & 58 & 13 \\
175 & 51 & 99 & 210 & 35 & 133 & 80 & 103 & 49 & 247 & 30 & 249 & 200 & 4 & 193 & 60 \\
248 & 83 & 65 & 139 & 135 & 9 & 106 & 238 & 29 & 90 & 18 & 227 & 187 & 121 & 250 & 110 \\
8 & 230 & 27 & 44 & 92 & 220 & 165 & 118 & 36 & 104 & 237 & 142 & 107 & 183 & 84 & 146 \\
85 & 102 & 203 & 69 & 73 & 5 & 16 & 159 & 24 & 128 & 168 & 41 & 39 & 52 & 17 & 20 \\
91 & 59 & 109 & 82 & 129 & 26 & 5 & 208 & 156 & 87 & 67 & 241 & 113 & 31 & 221 & 72 \\
122 & 198 & 115 & 42 & 6 & 70 & 240 & 127 & 10 & 160 & 232 & 239 & 57 & 38 & 197 & 138 \\
174 & 176 & 68 & 117 & 181 & 14 & 255 & 89 & 134 & 148 & 18 & 125 & 88 & 130 & 151 & 12 \\
171 & 213 & 112 & 145 & 154 & 66 & 147 & 28 & 48 & 224 & 201 & 98 & 120 & 226 & 114 & 202 \\
55 & 166 & 25 & 243 & 137 & 199 & 95 & 79 & 62 & 154 & 178 & 169 & 185 & 217 & 223 & 98 \\
153 & 167 & 235 & 177 & 7 & 253 & 225 & 162 & 155 & 22 & 192 & 157 & 180 & 97 & 179 & 126 \\
136 & 211 & 186 & 191 & 204 & 170 & 245 & 251 & 246 & 11 & 100 & 119 & 231 & 76 & 63 & 123 \\
190 & 164 & 184 & 212 & 182 & 163 & 172 & 43 & 94 & 105 & 161 & 242 & 219 & 1 & 19 & 215 \\
111 & 194 & 189 & 233 & 143 & 61 & 101 & 149 & 116 & 216 & 196 & 132 & 131 & 188 & 56 & 46 \\
\hline
\end{tabular}

Selanjutnya dilakukan proses Pseudo-Random Generation Algorithm (PRGA) sebanyak jumlah karakter plaintext agar dapat dihasilkan nilai $z$.

$\mathrm{I}=73$
$\mathrm{Q}=81$
$\mathrm{~B}=66$
$\mathrm{~A}=65$
$\mathrm{~L}=76$

Pada tahap awal inisialisasikan nilai $i=0, j=0, \mathrm{k}=0, \mathrm{z}=0$, dan $\mathrm{w}$ adalah bilangan acak yang merupakan bilangan GCD atau relatif prima dengan panjang S yaitu 256. Selanjutnya lakukan prosesseperti berikut:

$$
\begin{aligned}
i=i+w & =0+221 \bmod 256=221 \\
j=k+S[j+S[i]] & =0+S[0+S[221]] \bmod 256 \\
k=i+k+S[j] & =0+S[0+76] \bmod 256=S[76]=187 \\
& =221+0+S[187] \bmod 256 \\
& =221+0+169 \bmod 256=134 \\
S[i], S[j] & =S[i]=S[221]=76, S[j]=S[187]=169 \\
S w a p S[i] \text { with } S[j] & =S[i]=S[221]=169, S[j]=S[187]=76 \\
z=S[j+S[i+S[z+k]]] & =\mathrm{S}[187+\mathrm{S}[221+\mathrm{S}[0+134]]] \bmod 256 \\
& =\mathrm{S}[187+\mathrm{S}[221+240]] \bmod 256 \\
& =\mathrm{S}[187+\mathrm{S}[205] \bmod 256 \\
& =\mathrm{S}[187+97] \bmod 256 \\
& =\mathrm{S}[28] \bmod 256 \\
& =34
\end{aligned}
$$

Proses pencarian nilai z dilakukan untuk masing-masing karakter plaintext (sebanyak 5 kali) dengan cara yang sama seperti di atas, sehingga ditemukan nilai kunci untuk masing-masing karakter plaintext. Setelah melakukan proses Pseudo-Random Generation Algorithm (PRGA), maka nilai-nilai z akan dikonversi menjadi nilai biner.

Tabel 3. Nilai Desimal dan Biner Hasil Proses PRGA

\begin{tabular}{cccccc}
\hline Plaintext & I & Q & B & A & L \\
\hline Desimal & 73 & 81 & 66 & 65 & 76 \\
Biner & 01001001 & 01010001 & 01000010 & 01000001 & 01001100 \\
Output $z$ & 34 & 31 & 214 & 148 & 7 \\
Biner & 00100010 & 00011111 & 11010110 & 10010100 & 00000111 \\
\hline
\end{tabular}

Proses enkripsi dilakukan berdasarkan persamaan 1, yaitu melakukan operasi XOR antara biner plaintext dengan biner kunci yang dihasilkan dari proses PRGA.

Misalnya untuk mencari cipher dari karakter I, maka dilakukan proses berikut : 
Karakter "I" dengan nilai desimal 73 akan di XOR dengan nilai outup $z$ hasil perhitungan proses PRGA yang pertama yaitu 34, sehingga :

$73=01001001$

$34=\underline{00100010} \oplus$

$01101011=107$ dalam tabel ASCII merupakan karakter "k".

Proses ini dilakukan untuk masing-masing karakter plain, sehingga menghasilkan ciphertext yaitu "kNG̣õK".

2. Proses Embedding Spread Spectrum

Proses selanjutnya adalah melakukan penyembunyian data hasil enkripsi algoritma Spritz kedalam objek audio Mp3 menggunakan algoritma Spread Spectrum. Tahap awal proses penyisipan adalah penyebaran biner ciphertext “0110101101001110 $100101001101010101001011 ”$ dengan besaran tabel empat sehingga menghasilkan segmen baru sebagai berikut :

00001111111100001111000011111111
00001111000000001111111111110000
11110000000011110000111100000000
11111111000011110000111100001111
00001111000000001111000011111111

Selanjutnya dilakukan pembangkitan pseudonoise berdasarkan kata kunci yang digunakan dalam proses penyisipan. Operasi XOR dilakukan pada kata kunci untuk memperoleh nilai yang nantinya akan digunakan sebagai pembangkit bilangan acak. Proses pembangkitan pseudonoise adalah sebagai berikut :

$\mathrm{k} \quad=01101011$

$\mathrm{a} \quad=01100001 \mathrm{XOR}$

00001010

$\mathrm{m}=\underline{01101101} \mathrm{XOR}$

01100111

$\mathrm{i} \quad=\underline{01101001} \mathrm{XOR}$

$\overline{\mathbf{0 0 0 0 1 1 1 0}}=7($ desimal $)$

Nilai 7 yang diperoleh selanjutnya digunakan sebagai seed random untuk pembangkitan bilangan acak dengan rumus Linear Congruential Generator (LCG), dimana a $=17, \mathrm{c}=8$, dan $\mathrm{m}=84$. Nilai dari $\mathrm{a}=17, \mathrm{c}=8$, dan $\mathrm{m}=$ 84. Proses perhitungan pembangkitan bilangan acak dengan rumus Linear Congruential Generator(LCG) adalah sebagai berikut :

$\mathrm{X} 1=(17 \times 7+8) \bmod 84=43$

$\mathrm{X} 2=(17 \times 43+8) \bmod 84=67$

$\mathrm{X} 3=(17 \times 67+8) \bmod 84=55$

$\mathrm{X} 4=(17 \times 55+8) \bmod 84=19$

$\mathrm{X} 5=(17 \times 19+8) \bmod 84=79$

Demikian seterusnya untuk X6, X7, X8, X9, .... Xn

Biner-biner ciphertext yang sudah disebar berjumlah 160 bit, sehingga dari perhitungan LCG di atas diambil 20 angka yaitu 43, 67, 55, 19, 79, 7, 43, 67, 55, 19, 79, 7, 43, 67, 55, 19, 79, 7, 43, 67 dan dirubah ke dalam bentuk biner yang berjumlah 160 bit lalu akan digunakan sebagai pseudonoise. Bentuk biner pseudonoise adalah sebagai berikut :

$$
\begin{array}{llll}
00101011 & 01000011 & 00110111 & 00010011 \\
01001111 & 00000111 & 00101011 & 01000011 \\
00110111 & 00010011 & 01001111 & 00000111 \\
00101011 & 01000011 & 00110111 & 00010011 \\
01001111 & 00000111 & 00101011 & 01000011
\end{array}
$$

Selanjutnya dilakukan proses modulasi dengan menggunakan operasi XOR terhadap biner ciphertext dan biner pseudonoise, dimana setiap segmen biner ciphertext di XOR dengan setiap segmen biner pseudonoise. Proses modulasi dapat dilihat di bawah ini :

$$
\begin{array}{cc}
\text { Segmen } \text { ciphertext } 1 & =00001111111100001111000011111111 \\
\text { Segmen } \text { psoudonoise } 1 & =\frac{00101011010000110011011100010011}{\mathbf{0 0 1 0 0 1 0 0 1 0 1 1 0 0 1 1 1 0 0 0 1 1 1 1 1 1 0 1 1 1 0 0}}
\end{array}
$$

Sehingga menghasilkan biner-biner baru yaitu :

00100100010000111100011111101100
01000000000001111101010010110011
11000111000111000100000000000111
11010100010011000011100000011100
01000000000001111101101110111100


Kemudian biner-biner hasil modulasi disisipkan ke dalam audio mp3. Pada proses penyisipan akan ditambahkan sebuah karakter yang digunakan sebagai penanda akhir. Penanda akhir berguna untuk membatasi proses pengambilan bit-bit dari sampel audio stegano pada proses ekstraksi, dimana penanda akhir yang digunakan adalah karakter \# dalam biner 00100011. Penyisipkan dilakukan pada bit ke-8 nilai biner audio sampel dengan menukarkan atau memindahkan nilai bit pertama chipertext dengan nilai bit ke-8 byte pertama audio sampel, serta menyisipkan bit-bit penanda akhir. Adapun proses penyisipan atau perpindahan nilai biner chipertext dapat dilihat pada tabel di bawah ini :

Tabel 4. Proses Embedding Biner Ciphertext

\begin{tabular}{|c|c|c|c|c|c|c|c|c|}
\hline \multirow{2}{*}{ No } & \multicolumn{3}{|c|}{ Audio Cover } & \multirow{2}{*}{$\begin{array}{c}\text { Bit } \\
\text { Cipher }\end{array}$} & \multicolumn{4}{|c|}{ Stegano Audio } \\
\hline & Hex & Dec & Biner & & Biner & & Dec & Hex \\
\hline 1 & 49 & 73 & 01001001 & 0 & 0100100 & 0 & 72 & 48 \\
\hline 2 & $6 \mathrm{C}$ & 108 & 01101100 & 0 & 0110110 & 0 & 108 & $6 \mathrm{C}$ \\
\hline 3 & $6 \mathrm{D}$ & 109 & 01101101 & 1 & 0110110 & 1 & 109 & $6 \mathrm{D}$ \\
\hline 4 & 75 & 117 & 01110101 & 0 & 0111010 & 0 & 116 & 74 \\
\hline 5 & 20 & 32 & 00100000 & 0 & 0010000 & 0 & 32 & 20 \\
\hline 6 & $4 \mathrm{~B}$ & 75 & 01001011 & 1 & 0100101 & 1 & 75 & $4 \mathrm{~B}$ \\
\hline 7 & $6 \mathrm{~F}$ & 111 & 01101111 & 0 & 0110111 & 0 & 110 & $6 \mathrm{E}$ \\
\hline 8 & $6 \mathrm{D}$ & 109 & 01101101 & 0 & 0110110 & 0 & 108 & $6 \mathrm{C}$ \\
\hline 9 & 70 & 112 & 01110000 & 0 & 0111000 & 0 & 112 & 70 \\
\hline 10 & 75 & 117 & 01110101 & 1 & 0111010 & 1 & 117 & 75 \\
\hline $\begin{array}{l}\cdots \cdots \\
158\end{array}$ & B1 & $\begin{array}{l}\cdots \ldots \\
177\end{array}$ & $\begin{array}{c}\cdots \cdots \\
10110001\end{array}$ & 1 & $\begin{array}{r}\cdots \cdots \\
1011000\end{array}$ & 1 & $\begin{array}{l}\cdots \ldots \\
177\end{array}$ & B1 \\
\hline 159 & 66 & 102 & 01100110 & 0 & 0110011 & 0 & 102 & 66 \\
\hline 160 & $6 \mathrm{D}$ & 109 & 01101101 & 0 & 0110110 & 0 & 108 & $6 \mathrm{C}$ \\
\hline 161 & 96 & 150 & 10010110 & 0 & 1001011 & 0 & 150 & 96 \\
\hline 162 & 78 & 120 & 01111000 & 0 & 0111100 & 0 & 120 & 78 \\
\hline 163 & $9 \mathrm{D}$ & 157 & 10011101 & 1 & 1001110 & 1 & 157 & 9D \\
\hline 164 & 89 & 137 & 10001001 & 0 & 1000100 & 0 & 136 & 88 \\
\hline 165 & 78 & 120 & 01111000 & 0 & 0111100 & 0 & 120 & 78 \\
\hline 166 & B4 & 180 & 10110100 & 0 & 1011010 & 0 & 180 & B4 \\
\hline 167 & B1 & 177 & 10110001 & 1 & 1011000 & 1 & 177 & B1 \\
\hline
\end{tabular}

4. Proses Ekstraksi dan Dekripsi

Proses ekstraksi adalah kebalikan dari tahap-tahap proses embedding dan kunci yang digunakan pada proses ektraksi sama dengan proses embedding. Tahap awal adalah pengembalian bit-bit yang telah disisipkan dan dilanjutkan dengan proses pembangkitan pseudonoise berdasarkan kata kunci yang digunakan pada proses embedding, lalu dilakukan tahap demodulasi untuk mengembalikan ciphertext dengan menggunakanan operasi XOR terhadap bit-bit yang telah diambil dari proses penyisipan dengan bit-bit pseudonoise. Biner-biner hasil proses pseudonoise akan dikelompokkan menjadi 8 bit per kelompok, kemudian masing-masing kelompok biner tersebut akan di XOR dengan biner-biner kunci yang telah dibangkitkan berdasarkan algoritma spritz (proses dekripsi), sehingga dihasilkan plaintext.

\subsection{Hasil Pengujian}

Hasil pengujian proses enkripsi dan embedding sebanyak tiga sampel. Sampel hasil proses pengujian enkripsi dan embedding dapat dilihat pada tabel dibawah ini :

Tabel 5. Hasil Pengujian Proses Enkripsi dan Embeding

\begin{tabular}{|c|c|c|c|c|c|c|c|c|c|c|}
\hline No & File Text & $\begin{array}{c}\text { Kunci } \\
\text { Enkrip }\end{array}$ & $\begin{array}{c}\text { Chiper } \\
\text { text }\end{array}$ & $\begin{array}{c}\text { Cover Audio } \\
\text { mp3 }\end{array}$ & $\begin{array}{c}\text { Kunci } \\
\text { Embedd }\end{array}$ & $\begin{array}{c}\text { Audio } \\
\text { Stegano }\end{array}$ & $\begin{array}{l}\text { Waktu } \\
\text { proses }\end{array}$ & $\begin{array}{c}\text { MSE } \\
(\%)\end{array}$ & $\begin{array}{c}\text { PSNR } \\
\text { (dB) }\end{array}$ & Ket \\
\hline 1 & $\begin{array}{c}\text { IQBAL } \\
\text { Size : } \\
0.005 \mathrm{~KB}\end{array}$ & 2019 & kNG̣õK & $\begin{array}{l}\text { Aku.mp3 } \\
\text { Size : } \\
\text { 3.31 MB }\end{array}$ & kami & $\begin{array}{c}\text { audio1.mp3 } \\
\text { Size: } \\
\text { 3.51 MB }\end{array}$ & 4 detik & 23.2 & 32.01 & Berhasil \\
\hline 2 & $\begin{array}{c}\text { Kepada } \\
\text {............ } \\
\text { Kami } \\
\text { Size : } \\
\text { 4.330 KB }\end{array}$ & 1997 & $\begin{array}{c}\text { ÙÙAx } \\
\text { tðp } \\
\ldots \ldots \ldots . . . \\
\text { ÖÏß64 } \\
\text { (̇̀ }\end{array}$ & $\begin{array}{c}\text { Pelangi.mp3 } \\
\text { Size : } \\
\text { 3.38 MB }\end{array}$ & kamu & - & - & - & - & Gagal \\
\hline 3 & $\begin{array}{l}\text { COBA } \\
\text { Size : }\end{array}$ & 2018 & ûÓp“ & $\begin{array}{l}\text { Rakyat. } \\
\text { mp3 }\end{array}$ & Kita & $\begin{array}{c}\text { audio3.mp3 } \\
\text { Size }: 5.32\end{array}$ & 4 detik & 24.6 & 31.76 & Berhasil \\
\hline
\end{tabular}




$\begin{array}{ccc}0.004 \mathrm{~KB} & \text { Size }: & \mathrm{MB}\end{array}$

Berdasarkan tabel 5 proses enkripsi dan embedding berhasil dikarenakan audio Mp3 yang digunakan memiliki size lebih besar dari size ciphertext, sehingga cukup untuk menampung ciphertext. Proses enkripsi dan embedding gagal (pengujian sampel nomor 2) dikarenakan audio Mp3 yang digunakan memiliki size yang lebih kecil dari size ciphertext, sehingga tidak cukup menampung ciphertext.

\section{KESIMPULAN}

Berdasarkan analisa dan pengujian yang telah dilakukn pada penelitian ini, maka disimpulkan bahwa :

1. Pesan teks dengan format txt dapat diamankan dengan teknik kriptografi serta dapat disembunyikan ke dalam sebuah media berupa audio berformat Mp3 dengan teknik steganografi.

2. Algoritma Spritz dapat melakuakan proses enkripsi terhadap pesan teks menggunakan tiga tahap yaitu tahap Key Scheduling Algorithm (KSA), Prseudo-Random Generation Algorithm (PGRA) dan enkripsi dan dekripsi. Proses penyisipan yang menghasilkan nilai MSE kecil tidak berpengaruh banyak terhadap kualitas audio Mp3 sebab tingkat persen error yang terjadi lebih sedikit serta proses penyisipan yang menghasilkan nilai PSNR besar berpengaruh baik terhadap kualitas audio Mp3 sebab penyisipan tidak terlihat jelas.

3. Aplikasi yang dirancang menggunakan Microsoft Visual Basic Net 2010 berdasarkan tahap-tahap proses enkripsi dan dekripsi algoritma Spritz serta tahap-tahap proses emebedding dan ekstraksi algoritma Spread Spectrum dapat mempermudah proses pengamanan dan penyembunyian pesan teks ke dalam file audio Mp3.

\section{REFERENCES}

[1] Gunawan,"Kombinasi Algoritma Caesar Cipher dan Algoritma RSA Untuk Pengamanan File Dokumen Dan Pesan Teks", Jurnal Nasional Informatika dan Teknologi Jaringan, vol. 2, pp.124-129, 2018.

[2] M. Winafil, S. Sinurat and T. Zebua, "Implementasi Algoritma Advanced Encryption Standard dan Triple Data Encryption Standard Untuk Mengamankan Citra Digital," in KOMIK (Konferensi Nasional Teknologi Informasi dan Komputer), Medan, 2018.

[3] B. Prasetiyo , R. Gernowo dan B. Noranita,” Kombinasi Steganografi Berbasis Bit Matching dan Kriptografi DES untuk Pengamanan Data", Scientific Journal of Informatic, Vol. 1, pp.79-94, 2014.

[4] Sora, (2019,Feb.18). Pengertian Audio dan Media Audio Secara Lengkap [online]. Available: http://www.pengertianku.net/2014/11/pengertian-audio-dan-media-audio-secara-lengkap.html.

[5] T. Zebua,"Encoding The Record Database Of Computer Based Test Exam Based On Spritz Algorithm", Lontar Komputer, vol. 9, pp.52-62, 2018.

[6] M. M. Assyahid, Rihartanto dan D. S. B. Utomo,” Iplementasi Steganografi Pesan Text ke Dalam Audio Dengan Metode Spread Spectrum”, Prosiding Seminar Nasional Ilmu Komputer dan Teknologi Informasi, vol. 3, pp.27-34, 2018. 